1989). Dystonia was also reported in 3 of the 8 patients with L-2hydroxyglutaric acidemia.

\title{
MUCOPOLYSACCHARIDOSIS: MRI STUDY
}

Characteristic changes in the MRI of 2 brothers with mucopolysaccharidosis type I are reported from the Departments of Paediatrics, Neuroradiology and Neurology, University of Ancona, Italy. One patient was mentally retarded and the other had a normal IQ. The MRI showed a honeycomb-like appearance of the thalami, hypoplasia of the cerebellum and an enlarged ventricular system, with changes in the white matter behind the occipital horns. These changes were not correlated with the mental retardation. (Gabrielli O et al. Cerebral MRI in two brothers with mucopolysaccharidosis type I and different clinical phenotypes. Neuroradiology Aug 1992; 34:313-315.) (Correspondence: Dr. O. Gabrielli, Department of Pediatrics, University of Ancona, Via F. Corridoni 11, I-60123 Ancona, Italy.)

COMMENT. Glycosaminoglycans and glycolipids accumulate in the cells of the central nervous system in mucopolysaccharidosis type I. It is suggested that the mental retardation could be tied to neuronal damage caused by lysosomal storage of these substances. The cell biology of glycosaminoglycans in regulating normal cerebrospinal fluid absorption is reviewed by Knepper PA and McLone DG, Children's Memorial Hospital and Northwestern University Medical School, Chicago, (Pediat Neurol Sci 1986; 12:240-251).

\section{METABOLIC ALTERATIONS IN MULTIPLE SCLEROSIS}

Alterations in regional cerebral metabolism have been demonstrated by in vivo proton magnetic resonance spectroscopy of 8 children ( 7 - 16 years) with established multiple sclerosis at the Max-Planck-Institut fur biophysikalische Chemie, Postfach, and Abt. Kinderheilkunde, Schwerpunkr Neuropadiatrie, Georg-August-Universitat, Gottingen, Federal Republic of Germany. MS plaques showed a decrease in $\mathrm{N}$-acetylaspartate and creatines, and an increase in cholines and myo-inositol. Cortical gray matter related to MS lesions showed a reduction of $\mathrm{N}$-acetylaspartate. Functional impairment in MS was linked to gross metabolic disturbances of neuronal cell chemistry. (Bruhn $\mathrm{H}$ et al. Multiple sclerosis in children: cerebral metabolic alterations monitored by localized proton magnetic resonance spectroscopy in vivo. Ann Neurol Aug 1992; 32:140-150.) (Correspondence: Dr. Bruhn, Max-Planck-Institut fur biophysikalische Chemie, Postfach 2841, D-3400 Gottingen, Federal Republic of Germany.)

COMMENT. Proton magnetic resonance spectroscopy has revealed metabolic alterations associated with multiple sclerosis in focal lesions and in the adjacent cortex. The method could aid in the differentiation of MS plaques from other disorders and in monitoring response to therapy. For additional articles on MS in children see Progress in Pediatric Neurology, Millichap JG, 1991, 507-510. 